\title{
Effect of a calcitonin gene-related peptide- binding L-RNA aptamer on neuronal activity in the rat spinal trigeminal nucleus
}

\author{
Michael J. M. Fischer ${ }^{1,2}$, Jakob Schmidt ${ }^{1}$, Stanislav Koulchitsky ${ }^{1,3}$, Sven Klussmann ${ }^{4}$, Axel Vater ${ }^{4}$ \\ and Karl Messlinger ${ }^{1 *}$
}

\begin{abstract}
Background: Calcitonin gene-related peptide (CGRP) plays a major role in the pathogenesis of migraine and other primary headaches. Spinal trigeminal neurons integrate nociceptive afferent input from trigeminal tissues including intracranial afferents, and their activity is thought to reflect facial pain and headache in man. CGRP receptor inhibitors and anti-CGRP antibodies have been demonstrated to be therapeutically effective in migraine. In parallel, CGRP receptor inhibition has been shown to lower spinal trigeminal neuron activity in animal models of meningeal nociception.

Methods: In a rat model of meningeal nociception, single cell activity of neurons in the spinal trigeminal nucleus with meningeal afferent input was recorded to test a further pharmacological approach, scavenging CGRP with a CGRP-binding L-RNA oligonucleotide, the L-aptamer NOX-C89. Cumulative ascending doses of NOX-C89 were intravenously infused.

Results: Spontaneous activity of spinal trigeminal neurons did not change after 0.05 mg/kg NOX-C89, however, after additional infusion of $0.5 \mathrm{mg} / \mathrm{kg}$ and $5 \mathrm{mg} / \mathrm{kg} \mathrm{NOX-C89}$, spontaneous activity was dose-dependently reduced. Identical doses of a control L-aptamer had no effect. This pharmacological effect of NOX-C89 was observed 10-25 min after infusion, but no difference was detected in the period 0-5 min. For comparison, the previously investigated CGRP receptor antagonist olcegepant had reduced activity within 5 min after infusion. Alongside the reduced spontaneous activity, after infusion of NOX-C89 the heat-induced neuronal activity was abolished.
\end{abstract}

Conclusions: Scavenging CGRP by mirror-image RNA aptamers provides further evidence that this approach can be used to control spinal trigeminal activity.

Keywords: Migraine, Headache, Meningeal nociception

\section{Background}

The neuropeptide calcitonin gene-related peptide (CGRP), found in a subset of polymodal nociceptive afferents innervating intracranial tissues, is considered an important endogenous mediator in the generation of headaches. This notion is based on the observation that infusion of CGRP in migraineurs can trigger a migraine attack $[1,2]$ and, more importantly, inhibition of the CGRP system has been proven beneficial in migraine patients, whereby different ways of interfering with the CGRP system appear to be effective: Inhibition of CGRP release by triptans, CGRP

\footnotetext{
* Correspondence: karl.messlinger@fau.de

${ }^{1}$ Institute of Physiology and Pathophysiology, University of

Erlangen-Nürnberg, Universitätstrasse 17, D-91054 Erlangen, Germany

Full list of author information is available at the end of the article
}

receptor inhibition by gepants and scavenging CGRP or blocking its receptor by monoclonal antibodies.

\section{CGRP receptor antagonists}

The CGRP receptor antagonists olcegepant (BIBN4096BS) and telcagepant (MK-0974) independently showed efficacy in phase III studies for the acute treatment of migraine [3-5]. However, olcegepant was clinically not further pursued, because of poor oral bioavailability, and telcagepant revealed some liver toxicity indicated by elevated transaminases when it was given daily to test its prophylactic use [6] or to prevent menstrual migraine [7]. This unclear toxic side-effect is reminiscent of preclinical experiments indicating a role of CGRP in liver inflammation and regeneration $[8,9]$, but might also be unrelated to the 
pharmacological effect. A third CGRP receptor antagonist, ubrogepant (MK-162), which has a different molecular structure, has successfully passed phase IIb [10] showing that this strategy has not been exhausted.

We hypothesized a central site of action for CGRP, and the existing evidence on this issue has been reviewed extensively [11-13]. Briefly, CGRP does not excite or sensitize meningeal nociceptors [14], but there are several lines of evidence suggesting a central site of action of CGRP, including the observation that CGRP receptor inhibition microiontophoretically injected at the recording site can reduce spinal trigeminal activity [15]. The central trigeminal activity was inhibited by systemically applied CGRP antagonists but not when the substance was applied to the dura mater; also effects on activity markers in the trigeminal ganglion were lacking when olcegepant was systemically applied [16-18]. Positron emission tomography of the CGRP antagonist telcagepant showed a rapid permeation of the blood-brain barrier and complete CGRP receptor occupancy at high concentrations. The receptor occupancy of an effective antimigraine dose of telcagepant was lower than what is expected to be necessary [19], but useful levels of inhibition are rather based on general observations than any specific findings in headaches, and further depend on e.g. target desensitization, regional target composition or endogenous ligands [20].

\section{Scavenging strategies}

Scavenging CGRP is another approach to migraine treatment. This requires large molecules with good tolerability, and some biologically occurring molecular classes seem to be well suited in this respect. One group is certainly antibodies, which are widely used therapeutically [21, 22]. AntiCGRP antibodies, eptinezumab (ALD403 by Alder Biopharmaceuticals) galcanezumab (LY2951742 by Eli Lilly) and fremanezumab (TEV-48125 by Teva Pharmaceuticals), have a half-life of 21-48 days. The completed phase II trials for the prevention of migraine attacks in patients suffering from frequent migraine attacks showed promising results and the phase III trials are ongoing [23-26].

Another less explored option is chirally inverse Loligonucleotides (L-aptamers, also known as Spiegelmers). RNA aptamers in the naturally occurring Dconfiguration that are enzymatically degraded by nucleases. In contrast, L-aptamers are stable in blood, resulting in a long half-life [27]. Such mirror-image (L-)aptamers have been developed to target gonadotropin releasing hormone, enterotoxin $\mathrm{B}$, vasopressin, substance P, nociceptin, CCL2/MCP-1, amylin, ghrelin, hepcidin, CXCL12/SDF-1, C5a, sphingosine 1-phosphate and glucagon [27]. Three L-aptamers have passed clinical phase I and IIa trials. NOX-H94 for hepcidin completed a phase I trial (van Eijk et al.
2014), and NOX-E36 for CCL2 as well as NOX-A12 against CXCL12/SDF-1 have completed and published Phase IIa trials [28, 29]. Beyond stability, the rate of excretion is important for the plasma half-life. The latter can be prolonged by covalent coupling of polyethylene glycol moieties to these substances [30]. NOX-C89, a PEGylated variant of the first CGRP-binding L-aptamer, STAR-F12- $\Delta 43-48$ [31], that preferentially binds to mouse/rat $\alpha$ CGRP has been used to elucidate strain differences in rats regarding CGRP release and behavioral responses to noxious heat [32]. It was furthermore reported to reduce CGRP-dependent vasodilatation and blood flow in the exposed rat dura mater [33-35]. A newer anti$\alpha C G R P$ L-aptamer NOX-L41, with equal affinity to mouse/ rat $\alpha$ CGRP and an even higher affinity to human $\alpha$ CGRP, was shown to inhibit neurogenic plasma protein extravasation [36]. Before clinical validation, new strategies are tested in preclinical models $[34,37]$. We chose to investigate neuronal firing in the trigeminal pathway in rats following our prior study, in which we examined the effect of the CGRP receptor antagonist olcegepant. Neuronal activity in the trigeminal system, particularly in the neurons receiving input from the cranial dura mater, is assumed to reflect headache. Therefore, the effects of an anti-CGRP L-aptamer on neuronal activity in the spinal trigeminal nucleus were tested. This approach has limited output at relatively high effort, but can directly asses the activity considered to underlie headaches. To this end experiments on cats and rats are established. Results do not point to a higher predictive value for human disease for one of these species; the current study used rats as in our prior work investigating olcegepant. The purpose of this study was to investigate the effect of anti- $\alpha$ CGRP L-RNA oligomers on the spontaneous and heat-evoked firing of spinal trigeminal neurons as a model of meningeal nociception.

\section{Methods}

The experiments were performed in accordance with the ethical issues of the International Association for the Study of Pain 'IASP Guidelines for the Use of Animals in Research' and in compliance with the guidelines for the welfare of experimental animals of the Federal Republic of Germany and the European Commission (Directive 2010/63/EU). The experimental protocol was reviewed by an ethics committee and approved by the animal authority of the District Government of Mittelfranken or Unterfranken, Bavaria, Germany.

\section{Experimental procedures}

Wistar rats were bred in house and held in group cages with a $12 \mathrm{~h}$ light/dark cycle at a temperature of $21{ }^{\circ} \mathrm{C}$. Rats had a standard bedding material and access to pellet food and water ad libitum. Female rats were used for in house breeding, therefore male rats with a medium 
body weight of $365 \mathrm{~g}$ (range 300-480 g) were used for the experiments. Rats were drug naïve and had not undergone any procedures before the experiment. Details of the surgical and recording procedures were performed as described previously [16, 38]. Briefly, rats were anesthetized with either thiopental (Trapanal, Byk Gulden, Germany) as in prior investigations and with isoflurane once this was established. No difference in physiological parameters between the two regimes of anesthesia induction were apparent but the study was not powered to investigate this topic. For thiopental, an initial intraperitoneal dose of $120-150 \mathrm{mg} / \mathrm{kg}$ was injected, once the femoral vein was cannulated further adjustments were applied intravenously as indicated by nociceptive reflexes. Alternatively, the animals were placed into a closed box, which was supplemented by isoflurane $4 \%$ for rapid induction of anesthesia, continued with isoflurane $2.5 \%$ applied through a mask throughout the surgical procedures.

The right femoral artery was cannulated for monitoring arterial pressure and the right femoral vein to administer drugs. The animals were tracheotomized or intubated with an intravenous cannula (Vasuflo-T G14, Dispomed Witt, Germany). Atropine sulfate (B. Braun Melsungen AG, Melsungen, Germany, $0.5 \mathrm{mg} / \mathrm{ml} \mathrm{1:10} \mathrm{with} \mathrm{sodium}$ chloride $0.9 \%$ ) was injected subcutaneously to prevent salivation and muscle spasms. The animals were paralyzed with intravenous administration of gallamine triethiodide $(40 \mathrm{mg} / \mathrm{kg})$, and artificially ventilated with oxygen-enriched room air (about 30\% v/v). Expiratory $\mathrm{CO}_{2}$ was monitored and maintained at $4.5-5 \%$. Body temperature was maintained at $37-37.5^{\circ} \mathrm{C}$ with a feedbackcontrolled homeothermic system (TKM 0902, Föhr Medical Instruments, Seeheim-Jugenheim, Germany). During the experiment, an isoflurane concentration of $1.5-2.0 \%$ was adequate to maintain a constant depth of anesthesia as required to suppress nociceptive reflexes or blood pressure changes evoked by noxious pinch stimuli of the hindpaw and the earlobe. Vital parameters (blood pressure, heart rate, expiratory $\mathrm{CO}_{2}$ level, and body temperature) were continuously recorded throughout the experiment. The experiments were terminated with an overdose of thiopental followed by exsanguination.

\section{Head surgery and electrophysiological recordings}

The animal was placed in a stereotaxic frame with the head held in a fixed position by ear bars. The eyes were covered with dexpanthenol ointment (Bepanthen, Bayer Vital GmbH, Leverkusen, Germany) to prevent dehydration of the cornea. The skin overlying the skull was opened and the cranium exposed. Using a drill and fine forceps, a cranial window of $6 \mathrm{~mm}$ (rostro-caudal) and $4 \mathrm{~mm}$ (inferior-superior) was carefully cut into the left parietal bone to expose the dura mater. During surgery and throughout the experiment, the dura was protected from drying with isotonic saline. The neck muscles were divided along the animal's midline, and the medullary brain stem was exposed by cutting a window into the atlanto-occipital ligament and the underlying dura mater. For recordings custom-made carbon fiber glass microelectrodes (impedance 1-2 M 2 ) were used. Briefly, a gold-plated pin (diameter $1 \mathrm{~mm}$ ) was connected to a silver wire of about $10 \mathrm{~mm}$ length, then a $10 \mu \mathrm{m}$ thick carbon fiber was glued with conductive silver onto the wire. The fixed carbon fiber was sucked though a gentle airflow into a capillary (outer diameter $1.2 \mathrm{~mm}$, Science Products) and the silver wire was inserted into the end of the capillary and fixed by a drop of two-component adhesive. The other end of the capillary was pulled out in a vertical pipette puller (Narishige, Tokyo, Japan), so that the carbon fiber was fused into the tip. The end of the fiber sticking out of the tip was shortened by etching with $0.1 \mathrm{M}$ sulfuric acid under a microscope; ideally, the freely projecting carbon fiber tip is in the range of $20 \mu \mathrm{m}$. The microelectrode was inserted into the ipsilateral medulla and moved at steps of $2.5 \mu \mathrm{m}$ using a custom-made motor-driven microstepper, controlled by a nano-stepper type B unit (Scientific Precision Instruments, Oppenheim, Germany).

Electric pulses of $0.5 \mathrm{~ms}$ duration and $10-12 \mathrm{~V}$ were delivered at an interval of $5 \mathrm{~s}$ to the exposed dura through bipolar gold electrodes with their rounded tips touching the dural surface. Neurons in the subnucleus caudalis of the spinal trigeminal nucleus (STN) with input from meningeal afferents were identified by their regular discharge in response to electrical stimulation and by their responses to mechanical probing of the dura with von Frey filaments $(2.9-11.8 \mathrm{mN})$. Convergent afferent input from extracranial tissues was mapped by probing the ipsilateral cornea, temporal muscle, periosteum and facial skin with von Frey filaments and a fine blunt glass rod. Dural receptive fields were usually spotlike and located at or close to branches of the middle meningeal artery.

The extracellular signals were frequency filtered (high pass $100 \mathrm{~Hz}$, low-pass $5 \mathrm{kHz}$ ), amplified, and digitized at a sampling rate of $20 \mathrm{kHz}$ using a CED1402 controlled by spike2 software (Cambridge Electronic design, Cambridge, UK). Spike templates were generated off-line. The automatically generated templates in several runs with parameter adjustment were carefully considered to represent a single form, distinct from other signals. Thermally evoked action potentials were additionally used as templates to confirm the selected spikes. Thermally evoked action potentials were additionally used as templates to confirm the selected spikes. The position of recording sites was determined by measuring the distance caudal and lateral to the obex and by reading the depth of the microdrive. The center of the recordings was $2.4 \mathrm{~mm}$ 
caudal and $1.7 \mathrm{~mm}$ lateral of the obex; the average depth was $0.68 \mathrm{~mm}$.

\section{Experimental protocols}

Throughout the experiment, the rate of impulses per second was visualized and recorded for a control period of at least $20 \mathrm{~min}$ before application of substances. CGRP binding L-aptamer NOX-C89 and the control L-aptamer were synthesized and provided by NOXXON Pharma AG, Berlin. First, animals were dosed with $0.05 \mathrm{mg} / \mathrm{kg}$, about $26 \mathrm{~min}$ later with $0.5 \mathrm{mg} / \mathrm{kg}$ and another $26 \mathrm{~min}$ later with $5 \mathrm{mg} / \mathrm{kg}$. Substances were applied in a volume of $300 \mu \mathrm{l}$ with an infusion pump at a rate of $120 \mu \mathrm{l} / \mathrm{min}$ over a period of $2.5 \mathrm{~min}$. Consecutive experiments alternatingly tested NOX-C89 and the control L-aptamer. Baseline data between animals of experimental groups were not different.

Using a feedback-controlled vortex thermode [39], the surface temperature of the dura was kept at $32{ }^{\circ} \mathrm{C}$. Thermal stimulation before and after every drug administration included two heat and one cold stimulation protocols as described previously [16]. The first heat stimulus consisted of a ramp with a slope of $0.1{ }^{\circ} \mathrm{C} / \mathrm{s}$ from $32{ }^{\circ} \mathrm{C}$ to $44{ }^{\circ} \mathrm{C}$. After $180 \mathrm{~s}$ at $32{ }^{\circ} \mathrm{C}$ the dura was heated to 36,40 and $44{ }^{\circ} \mathrm{C}$ within $2 \mathrm{~s}$ in consecutive steps, each held for $30 \mathrm{~s}$. After another $180 \mathrm{~s}$ at $32{ }^{\circ} \mathrm{C}$, the temperature was decreased over $2 \mathrm{~s}$ to 26 and $20{ }^{\circ} \mathrm{C}$, held for $30 \mathrm{~s}$ each, then returned to baseline. From each of 16 male Wistar rats, one neuron in the caudal subnucleus of the STN was recorded for the full protocol duration as described previously [40]. Sample size was based on the variance of neuronal activity observed in previous experiments.

\section{Substances}

The CGRP-binding L-aptamer NOX-C89 consist of 42 nucleotides and has a molecular weight of $13.8 \mathrm{kDa}$, which is increased to a total of $54 \mathrm{kDa}$ by addition of $40 \mathrm{kDa}$ Y-shaped polyethylene glycol. NOX-C89 was initially dissolved as stock solution of $5 \mathrm{mg} / \mathrm{ml}$ in Dulbecco's phosphate buffered saline with $\mathrm{Ca}^{2+} / \mathrm{Mg}^{2+}$ and further diluted in the same solution before intravenous infusion. The CGRP binding L-aptamer NOX-C89 was a slightly modified variant of STAR-F12- $\Delta 43-48$ [31] for improved synthesis. The nuclease resistant mirror-image (L-)RNA oligonucleotide has the sequence:

5'-GGACUGAUGG CGCGGUCCUA UUACGCCGAU AGGGUGAGGG GA-3', which is PEGylated at its 5' end via an aminohexyl-linker. The synthesis of this molecule has briefly been described [33]. In another series of control experiments, a non-functional control L-aptamer with the reverse nucleotide sequence of NOX-C89 was applied with the same experimental protocol.

\section{Data analysis}

Results of two dependent samples were compared by Wilcoxon test for $n<10$. Results from the two experimental groups and repetitive measurements were compared by ANOVA, followed by an LSD post hoc test. Normalized activity at single time-points was compared against $100 \%$ using a one-sample $t$-test. All tests were performed by the Statistica (StatSoft, USA) software package. All values are given as mean \pm sem. Differences were considered significant at $p<0.05$.

\section{Results \\ General properties of units}

All units had low threshold facial receptive fields predominantly in the ophthalmic region. The mean rate of spontaneous activity was $21 \pm 7 \mathrm{imp} / \mathrm{min}$ (range $0.5-79$ $\mathrm{imp} / \mathrm{min})$.

\section{Effects of NOX-C89 on the spontaneous activity}

After a control period of $20 \mathrm{~min}$, intravenous infusion of the anti-CGRP L-aptamer NOX-C89 in three ascending doses caused a reduction in activity compared with control experiments (8 neurons in both groups, ANOVA, $\mathrm{F}_{3,42}=3.6, p=0.032$, Fig. 1a). While NOX-C89 $0.05 \mathrm{mg} / \mathrm{kg}$ had no significant effect, the infusion of $0.5 \mathrm{mg} / \mathrm{kg}$ and $5 \mathrm{mg} / \mathrm{kg}$ reduced neuronal activity in the period 10 $25 \mathrm{~min}$ after infusion compared with experiments with the control L-aptamer $(p=0.042$ and 0.039 , LSD post hoc tests). Activity in the control group did not change significantly compared with the baseline before the first infusion. In the NOX-C89 group, neuronal activity was reduced to $70 \%$ after $0.5 \mathrm{mg} / \mathrm{kg}$ and to $54 \%$ after further $5 \mathrm{mg} / \mathrm{kg}$ compared with activity before the first infusion $(p=0.014$, $p=0.039$, single sample $t$-test vs $100 \%$, Fig. 1b).

\section{Effects of thermal stimulation}

Increasing the local temperature on the dura mater in a ramp- or step-like mode caused an increase in neuronal activity (Fig. 2). During increased temperature (ramp from $32{ }^{\circ} \mathrm{C}$ to $44{ }^{\circ} \mathrm{C}$ within $18 \mathrm{~s}, 44{ }^{\circ} \mathrm{C}$ held for $30 \mathrm{~s}$ ) the activity was $207 \pm 77 \%$ compared with a $30 \mathrm{~s}$ control period before the stimulation (ANOVA, $\mathrm{F}_{(1,32)}=4.8, p=0.011$, LSD post hoc test). The temperature steps caused a temperaturedependent increase in activity. The average activity at $36{ }^{\circ} \mathrm{C}$ was $133 \pm 21 \%$, at $40{ }^{\circ} \mathrm{C} 142 \pm 19 \%$ and at $44{ }^{\circ} \mathrm{C} 172 \pm 15 \%$ of the $30 \mathrm{~s}$ control period before the stimulation (ANOVA, $\mathrm{F}_{(9,96)}=2.1, p=0.015,0.002$ and 0.001 , LSD post hoc tests). The thermal stimulation protocols were designed with different rates of temperature changes to detect phasic responses. Compared with the control period, evoked activity was $175 \pm 18 \%$ in the first $10 \mathrm{~s}$ of the temperature increase and $133 \pm 21 \%$ in the last $10 \mathrm{~s}$ of the temperature plateau. As previously reported, cooling of the dura did not change neuronal activity (data not shown). 

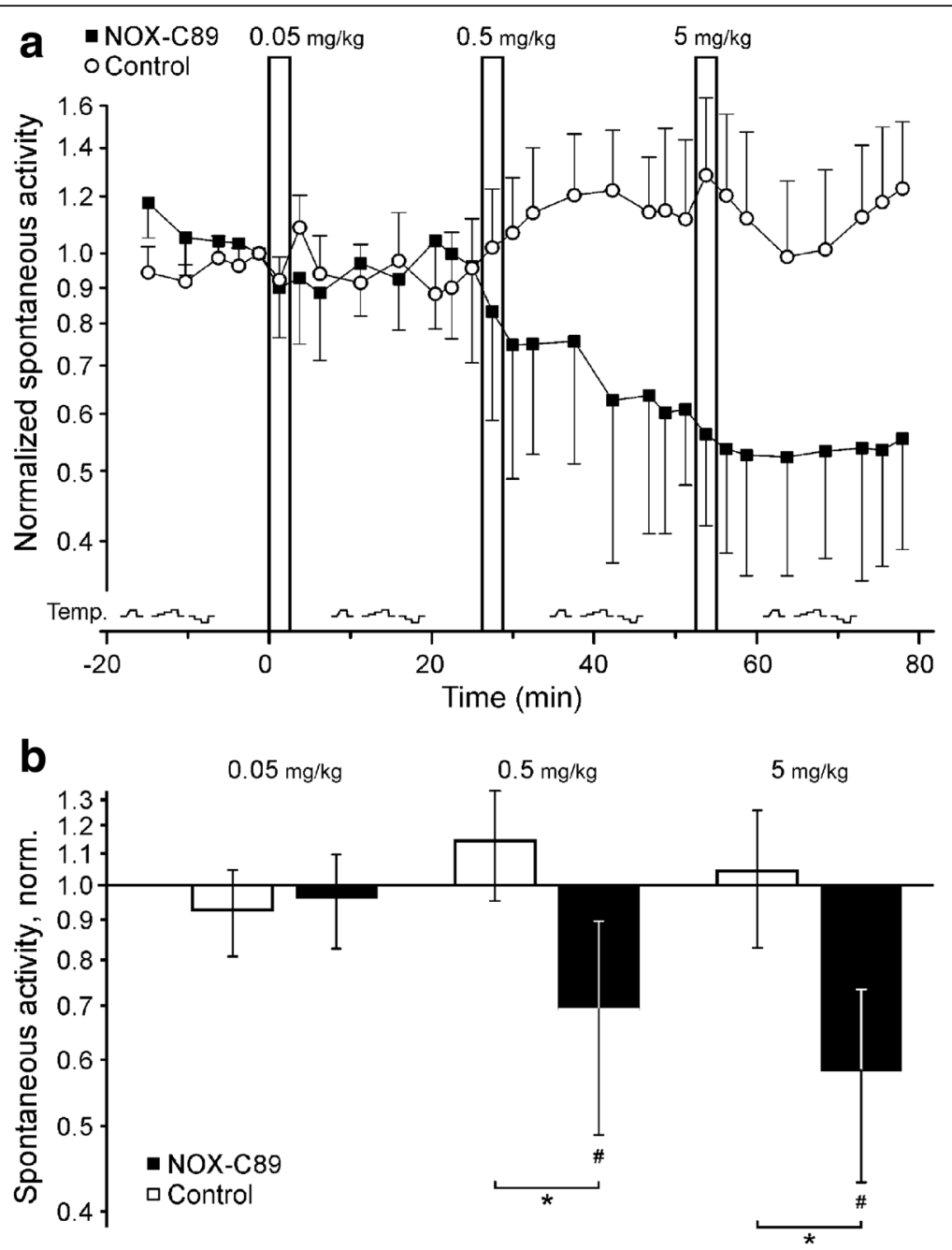

Fig. 1 Anti-CGRP L-aptamer NOX-C89 reduces spontaneous neuronal activity. a Normalized activity of spinal trigeminal neurons. After infusion of NOX-C89, spontaneous activity was reduced. In contrast, infusion of the control L-aptamer did not alter neuronal activity. For both groups eight separate experiments were performed, symbols represent activity per $150 \mathrm{~s}$. Note the longer intervals used for thermal testing, the heat and cold protocols are visualized at the bottom. b Twenty minutes after the infusion of NOX-C89 $0.5 \mathrm{mg} / \mathrm{kg}$ and $5 \mathrm{mg} / \mathrm{kg}$ the spontaneous neuronal activity was reduced, both in comparison to baseline activity at the beginning of the experiment (7.5 min period before the first injection, $\# p<0.05$ ) and to the control group $\left({ }^{*} p<0.05\right)$. Data are mean \pm SEM

\section{Effects of NOX-C89 on the activity evoked by thermal stimulation}

Compared with initial thermal responses before NOX-C89 infusion, none of the thermal stimulations thereafter caused an increase in neuronal activity (temperature ramp: $p=0.18$, 0.82 and 0.92 , temperature steps $p=0.78,0.81$ and 0.70 for $0.05,0.5$ and $5 \mathrm{mg} / \mathrm{kg}$, respectively, LSD post hoc tests).

\section{Discussion}

Systemic infusion of an anti-CGRP L-aptamer slowly reduced spontaneous as well as heat-induced rat spinal trigeminal activity.

All recorded units had some spontaneous activity, and it cannot be excluded that experimental procedures contributed to the observed spontaneous activity. Experiments were performed in close adherence to the protocol used and published in a previous paper, investigating olcegepant [16]. Like the receptor antagonist, the CGRPneutralizing L-aptamer NOX-C89 reduced spontaneous activity, however, only at a longer latency. In contrast to olcegepant, within 5 min after NOX-C89 application, no significant lowering of activity was observed. An explanation for this difference might be the molecular weight difference, i.e. the bulkier and charged NOX-C89 might have a slower uptake kinetic into the relevant compartment.

\section{Comparison to NOX-C89 effects in other studies}

In a previous paper, a positive association of CGRP expression levels with heat sensitivity was demonstrated. The thermal sensitivity of mice expressing abundant 

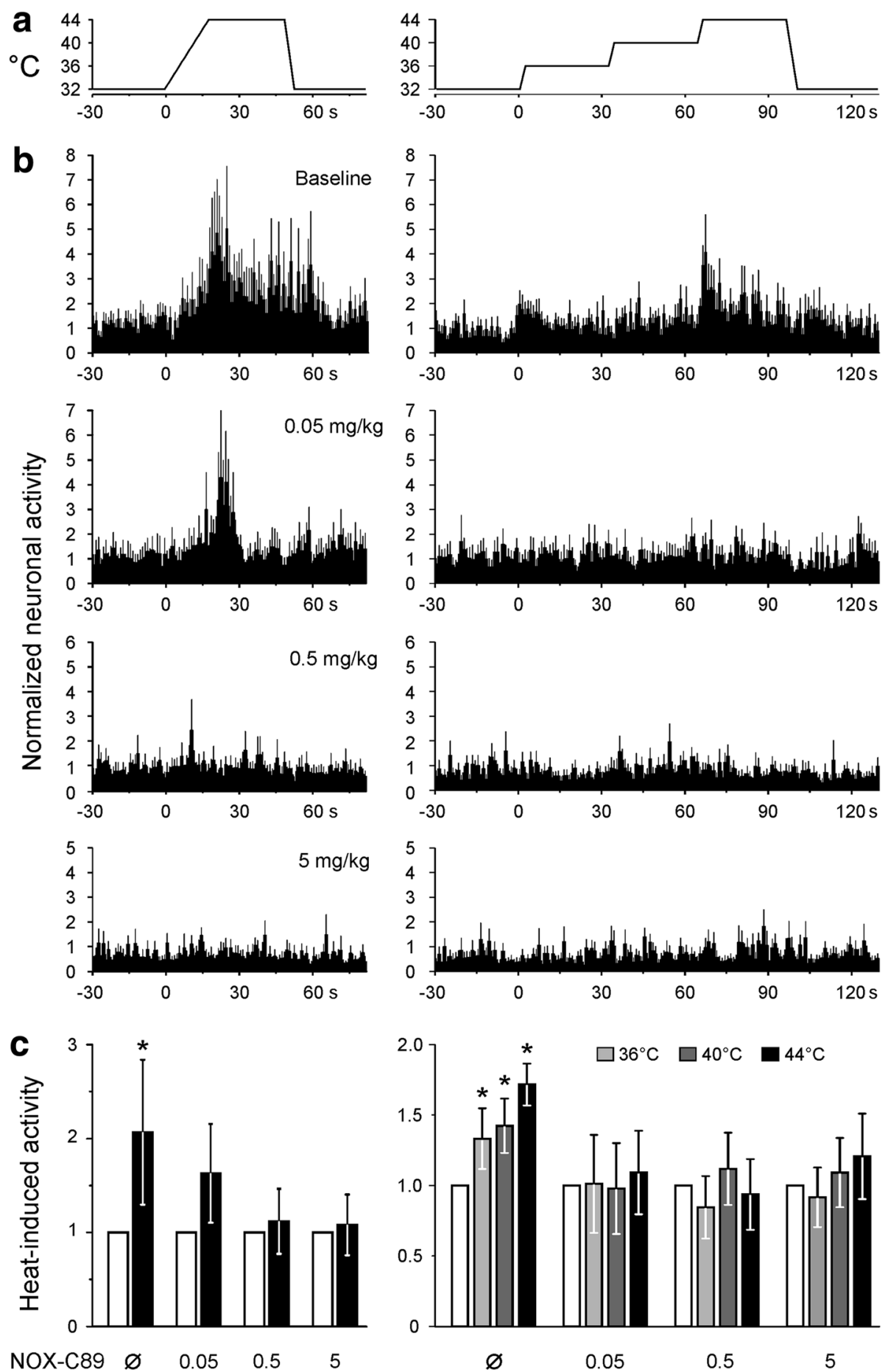

Fig. 2 Heat evoked activity of units with afferent input from the exposed cranial dura mater recorded in the spinal trigeminal nucleus caudalis. a Heat sensitivity was obtained at baseline and after all infusions as visualized and at the time points shown in Fig. 1. The temperature at the dura was first ramped from 32 to $44{ }^{\circ} \mathrm{C}$ and held for $30 \mathrm{~s}$. In a second protocol, the temperature was rapidly stepped from 32 to 36,40 and $44{ }^{\circ} \mathrm{C}$. $\mathbf{b}$ The response of eight spinal trigeminal neurons at baseline and after incremental additions of NOX-C89 0.05-5 mg/kg (mean \pm sem) during the temperature protocols shown in panel A. c Average activity during the whole period of elevated temperature was increased above baseline. Similarly, all temperature steps increased neuronal activity. NOX-C89 infusion at all doses inhibited the neuronal response to thermal stimulation ( $\left.{ }^{*} p<0.05\right)$. Data are mean \pm SEM 
CGRP was lowered after scavenging CGRP [32], which is consistent with our results. We have reported previously that NOX-C89 applied locally to the dura inhibited electrically evoked blood flow increases; a dose of $5 \mathrm{mg} / \mathrm{kg}$ reduced the evoked blood flow increases to $66 \%$ of the control [33]. This is similar to the $54 \%$ of remaining spinal trigeminal activity after a cumulative dose of $5.55 \mathrm{mg} / \mathrm{kg}$ in the present study, although it is unclear how well the vascular responses, which are frequently used as surrogates of the afferent activity due to their CGRP release, really correlate to neuronal activity [41, 42]. In a pressure myography of rat meningeal arteries in vitro, NOX-C89 reduced CGRP-induced dilatation when applied abluminally $\left(\mathrm{IC}_{50} 20 \mathrm{nM}\right)$, but not luminally, indicating the requirement of sufficient CGRP concentration at the smooth muscle cells [34]. In vivo, NOX-C89 $1 \mathrm{mg} / \mathrm{kg}$ caused about $80 \%$ inhibition of the CGRP-induced dilatation in rat dural and pial arteries compared with the response before the CGRP scavenger [35]. A minimum period of $30 \mathrm{~min}$ was between NOX-C89 infusion and the second CGRP-testing, which might be necessary for NOX-C89 distribution. This would be consistent with our finding of a slower onset of the NOX-C89 effect compared with olcegepant.

\section{Spinal trigeminal activity}

Reduction of spontaneous activity and reduced thermal responsiveness were detected at different doses but occurred largely together. One could hypothesize that the activity of the spinal trigeminal neurons, which is at least partly driven by the activity of primary afferent neurons [43], is inhibited by targeting CGRP. This would explain the suppression of thermal responses, as there is no reason to assume that the peripheral terminals of the neurons lost their heat sensitivity. Considering that both NOX-C89 as well as olcegepant reduced the activity to about half in high doses, one might further hypothesize that the remainder is an independently driven spinal trigeminal neuron background activity.

\section{NOX-C89 site of action}

CGRP secretion from primary afferents in the dorsal horn enhances thermal and mechanical nociceptive sensitivity $[44,45]$. A simple assay to measure CGRP at this site has been developed $[46,47]$. Considering the central site of action of CGRP receptor antagonists outlined in the introduction: Why would scavenging CGRP by a substance not necessarily penetrating the blood-brainbarrier be beneficial? A potential answer would be a site of action outside the blood-brain-barrier. In case the site of action is inside the blood-brain barrier, a low level of penetration might be sufficient or the tightness of the barrier is, at least temporary, altered. The latter is also a controversial issue, but there are studies in favor of this hypothesis, e.g. S100b plasma levels were associated with migraine attacks and are considered an index for blood-brain barrier alteration [48]. It should be mentioned that an effect of the anesthetic in this respect cannot be excluded. Extravasation of a fluorescently labeled version of the CGRP-neutralizing L-aptamer NOX-L41 (50 L-nucleotides conjugated to $40 \mathrm{kDa}$ polyethylene gly$\mathrm{col}$ and Alexa488) in the dura mater started to become visible $5 \mathrm{~min}$ after administration and increased for about $2 \mathrm{~h}$. Fluorescence was not detected in deeper cortical layers (below $55 \mu \mathrm{m}$ ), showing that NOX-L41-Alexa488 extravasates from dural but not from cortical vessels [36].

\section{Thermoresponses}

A high amount of dural nociceptors, similar to the nociceptors throughout the body, are sensitive to thermal stimuli. The observed temperature responses are coding only rapid changes well; the required rate of change does not naturally occur at the dura. Therefore, the thermal stimuli should be considered an experimental means to assess the responsiveness of the respective afferents. We have demonstrated that these stimuli in turn affect meningeal perfusion [49]. The sensitization of primary meningeal afferents by inflammatory agents involved in migraine has been demonstrated [50]. An attempt to explain the thermal sensitivity is lowering of the thermal threshold below the local temperature by sensitizing inflammatory mediators. This mechanism has been demonstrated for peripheral neurons [51] but seems rather hypothetical given the minimal proportional response of dural afferent neurons.

\section{Comparison to other approaches targeting the CGRP system}

The plasma half-life of L-RNA aptamers is about 1-2 days. This is much longer than the biologically occurring D-RNAs, and is not governed by degradation but by uptake into phagocytes, such as hepatic Kupffer cells. While there is no general rule for small molecules, the typical IgG antibody half-life in serum is around 20 days [52]. As mentioned above, eptinezumab galcanezumab and fremanezumab have a half-life above 20 days, which is appreciated if this successfully translates to long intervals between applications for prophylactic use. The molecular weight of NOX-C89 is about $54 \mathrm{kDa}$ compared with the anti-CGRP antibodies with about $145 \mathrm{kDa}$. There are currently no efforts for a further clinical development of NOX-C89 or its follow-up candidate NOX-L41, but this might become more attractive in case the anti-CGRP antibodies are effective but need to be abandoned for unforeseen reasons.

\section{Conclusion}

L-aptamer NOX-C89, belonging to a new chemical class of CGRP scavengers, was demonstrated to reduce 
spontaneous and thermally evoked activity in the spinal trigeminal nucleus neurons. Three L-aptamers have shown good safety and efficacy in clinical trials, and insights from these trials might help to progress the scavenging of CGRP as a therapeutic principle in migraine and possibly other headaches.

\section{Abbreviation}

L-aptamer: Oligonucleotide in the unnatural L-configuration, also known as Spiegelmer, which has been designed to bind to a biological target of interest

\section{Acknowledgements}

We like to thank Jana Schramm and Birgit Vogler for excellent technical assistance and Dr. Dirk Eulberg (NOXXON Pharma AG, Berlin) for valuable advice on the manuscript.

\section{Funding}

This work was supported by the interdisciplinary center for clinical research (IZKF) at the Friedrich-Alexander-University of Erlangen-Nürnberg to MJMF and the Noxxon Pharma, Berlin. Funding did in no way affect study design, collection, analysis, or interpretation of data.

\section{Availability of data and materials}

All data are available on request.

\section{Authors' contributions}

MJMF, JS and SK performed experiments. MJMF analyzed data, generated the figures and drafted the manuscript. AV and SK developed NOX-C89 and guided the experimental design. KM designed the study and critically revised the manuscript. All authors read and approved the manuscript.

\section{Ethics approval and consent to participate}

As mentioned in the methods section, the experimental protocol was reviewed by an ethics committee and approved by the District Government of Unterfranken, Bavaria, Germany.

\section{Consent for publication}

Not applicable.

\section{Competing interests}

The authors declare that they have no competing interests.

\section{Publisher's Note}

Springer Nature remains neutral with regard to jurisdictional claims in published maps and institutional affiliations.

\section{Author details}

${ }^{1}$ Institute of Physiology and Pathophysiology, University of Erlangen-Nürnberg, Universitätstrasse 17, D-91054 Erlangen, Germany. ${ }^{2}$ Center for Physiology and Pharmacology, Medical University of Vienna, Vienna, Austria. ${ }^{3}$ Department of Pharmacology, University of Liège, Liège, Belgium. ${ }^{4}$ Aptarion Biotech, Berlin, Germany.

Received: 6 October 2017 Accepted: 29 December 2017

Published online: 15 January 2018

\section{References}

1. Lassen LH, Haderslev PA, Jacobsen VB et al (2002) CGRP may play a causative role in migraine. Cephalalgia Int J Headache 22:54-61. https:/doi.org/10.1046/j. 1468-2982.2002.00310.x

2. Hansen JM, Hauge AW, Olesen J, Ashina M (2010) Calcitonin gene-related peptide triggers migraine-like attacks in patients with migraine with aura. Cephalalgia Int J Headache 30:1179-1186. https://doi.org/10.1177/ 0333102410368444

3. Olesen J, Diener H-C, Husstedt IW et al (2004) Calcitonin gene-related peptide receptor antagonist BIBN 4096 BS for the acute treatment of migraine. N Engl J Med 350:1104-1110. https://doi.org/10.1056/NEJMoa030505
4. Ho TW, Mannix LK, Fan X et al (2008) Randomized controlled trial of an oral CGRP receptor antagonist, MK-0974, in acute treatment of migraine. Neurology 70:1304-1312. https://doi.org/10.1212/01.WNL.0000286940.29755.61

5. Connor KM, Shapiro RE, Diener H-C et al (2009) Randomized, controlled trial of telcagepant for the acute treatment of migraine. Neurology 73:970-977. https://doi.org/10.1212/WNL.0b013e3181b87942

6. Ho TW, Connor KM, Zhang Y et al (2014) Randomized controlled trial of the CGRP receptor antagonist telcagepant for migraine prevention. Neurology 83:958-966. https://doi.org/10.1212/WNL.0000000000000771

7. Ho TW, Ho AP, Ge YJ et al (2016) Randomized controlled trial of the CGRP receptor antagonist telcagepant for prevention of headache in women with perimenstrual migraine. Cephalalgia Int J Headache 36:148-161. https://doi. org/10.1177/0333102415584308

8. Kroeger I, Erhardt A, Abt D et al (2009) The neuropeptide calcitonin generelated peptide (CGRP) prevents inflammatory liver injury in mice. J Hepatol 51:342-353. https://doi.org/10.1016/j.jhep.2009.03.022

9. Mizutani T, Yokoyama Y, Kokuryo T et al (2013) Calcitonin gene-related peptide regulates the early phase of liver regeneration. J Surg Res 183:138-145. https://doi.org/10.1016/j.jss.2012.11.028

10. Voss T, Lipton RB, Dodick DW et al (2016) A phase Ilb randomized, doubleblind, placebo-controlled trial of ubrogepant for the acute treatment of migraine. Cephalalgia Int J Headache 36:887-898. https://doi.org/10.1177/ 0333102416653233

11. Messlinger K, Fischer MJM, Lennerz JK (2011) Neuropeptide effects in the trigeminal system: pathophysiology and clinical relevance in migraine. Keio Med 60:82-89

12. Tfelt-Hansen P, Olesen J (2011) Possible site of action of CGRP antagonists in migraine. Cephalalgia Int J Headache 31:748-750. https://doi.org/10.1177/ 0333102411398403

13. Dux MJ, Messlinger KB (2015) New options for migraine treatment: focus on CGRP-blocking antibodies. Drugs Future 40:589-599. https://doi.org/10. 1358/dof.2015.040.09.2383047

14. Levy D, Burstein R, Strassman AM (2005) Calcitonin gene-related peptide does not excite or sensitize meningeal nociceptors: implications for the pathophysiology of migraine. Ann Neurol 58:698-705. https://doi.org/10. 1002/ana.20619

15. Storer RJ, Akerman S, Goadsby PJ (2004) Calcitonin gene-related peptide (CGRP) modulates nociceptive trigeminovascular transmission in the cat. $\mathrm{Br}$ J Pharmacol 142:1171-1181. https://doi.org/10.1038/sj.bjp.0705807

16. Fischer MJM, Koulchitsky S, Messlinger K (2005) The nonpeptide calcitonin gene-related peptide receptor antagonist BIBN4096BS lowers the activity of neurons with meningeal input in the rat spinal trigeminal nucleus. J Neurosci 25:5877-5883. https://doi.org/10.1523/JNEUROSCI.0869-05.2005

17. Sixt M-L, Messlinger K, Fischer MJM (2009) Calcitonin gene-related peptide receptor antagonist olcegepant acts in the spinal trigeminal nucleus. Brain J Neurol 132:3134-3141. https://doi.org/10.1093/brain/awp168

18. Koulchitsky S, Fischer MJM, Messlinger K (2009) Calcitonin gene-related peptide receptor inhibition reduces neuronal activity induced by prolonged increase in nitric oxide in the rat spinal trigeminal nucleus. Cephalalgia Int Headache 29:408-417. https://doi.org/10.1111/j.1468-2982.2008.01745.x

19. Hostetler ED, Joshi AD, Sanabria-Bohórquez $\mathrm{S}$ et al (2013) In vivo quantification of calcitonin gene-related peptide receptor occupancy by telcagepant in rhesus monkey and human brain using the positron emission tomography tracer [11C]MK-4232. J Pharmacol Exp Ther 347:478-486. https://doi.org/10. 1124/jpet.113.206458

20. Grimwood S, Hartig PR (2009) Target site occupancy: emerging generalizations from clinical and preclinical studies. Pharmacol Ther 122:281-301. https://doi. org/10.1016/j.pharmthera.2009.03.002

21. Barbanti P, Aurilia C, Fofi L et al (2017) The role of anti-CGRP antibodies in the pathophysiology of primary headaches. Neurol Sci off J Ital Neurol Soc Ital Soc Clin Neurophysiol 38:31-35. https://doi.org/10.1007/s10072-017-2907-8

22. Tso AR, Goadsby PJ (2017) Anti-CGRP monoclonal antibodies: the next era of migraine prevention? Curr Treat Options Neurol 19:27. https://doi.org/10. 1007/s11940-017-0463-4

23. Dodick DW, Goadsby PJ, Spierings ELH et al (2014) Safety and efficacy of LY2951742, a monoclonal antibody to calcitonin gene-related peptide, for the prevention of migraine: a phase 2, randomised, double-blind, placebocontrolled study. Lancet Neurol 13:885-892. https://doi.org/10.1016/S14744422(14)70128-0

24. Dodick DW, Goadsby PJ, Silberstein SD et al (2014) Safety and efficacy of ALD403, an antibody to calcitonin gene-related peptide, for the prevention 
of frequent episodic migraine: a randomised, double-blind, placebo-controlled, exploratory phase 2 trial. Lancet Neurol 13:1100-1107. https:/doi.org/10.1016/ S1474-4422(14)70209-1

25. Bigal ME, Dodick DW, Rapoport AM et al (2015) Safety, tolerability, and efficacy of TEV-48125 for preventive treatment of high-frequency episodic migraine: a multicentre, randomised, double-blind, placebo-controlled, phase 2b study. Lancet Neurol 14:1081-1090. https://doi.org/10.1016/S14744422(15)00249-5

26. Sun H, Dodick DW, Silberstein S et al (2016) Safety and efficacy of AMG 334 for prevention of episodic migraine: a randomised, double-blind, placebocontrolled, phase 2 trial. Lancet Neurol 15:382-390. https://doi.org/10.1016/ S1474-4422(16)00019-3

27. Vater A, Klussmann S (2015) Turning mirror-image oligonucleotides into drugs: the evolution of Spiegelmer $\left.{ }^{(}\right)$therapeutics. Drug Discov Today 20:147-155. https://doi.org/10.1016/j.drudis.2014.09.004

28. Menne J, Eulberg D, Beyer D et al (2017) C-C motif-ligand 2 inhibition with emapticap pegol (NOX-E36) in type 2 diabetic patients with albuminuria. Nephrol Dial Transplant Off Publ Eur Dial Transpl Assoc - Eur Ren Assoc 32:307-315. https://doi.org/10.1093/ndt/gfv459

29. Ludwig H, Weisel K, Petrucci MT et al (2017) Olaptesed pegol, an antiCXCL12/SDF-1 Spiegelmer, alone and with bortezomib-dexamethasone in relapsed/refractory multiple myeloma: a phase lla study. Leukemia 31:997-1000. https://doi.org/10.1038/leu.2017.5

30. Hoffmann S, Hoos J, Klussmann S, Vonhoff S (2011) RNA aptamers and spiegelmers: synthesis, purification, and post-synthetic PEG conjugation. Curr Protoc nucleic acid Chem chapter 4:unit 4.46.1-30. doi: https://doi.org/ 10.1002/0471142700.nc0446s46

31. Vater A, Klussmann S (2003) Toward third-generation aptamers: Spiegelmers and their therapeutic prospects. Curr Opin Drug Discov Devel 6:253-261

32. Mogil JS, Miermeister F, Seifert F et al (2005) Variable sensitivity to noxious heat is mediated by differential expression of the CGRP gene. Proc Natl Acad Sci U S A 102:12938-12943. https://doi.org/10.1073/pnas.0503264102

33. Denekas T, Tröltzsch M, Vater A et al (2006) Inhibition of stimulated meningeal blood flow by a calcitonin gene-related peptide binding mirror-image RNA oligonucleotide. Br J Pharmacol 148:536-543. https://doi.org/10.1038/sj.bjp. 0706742

34. Edvinsson L, Nilsson E, Jansen-Olesen I (2007) Inhibitory effect of BIBN4096BS, CGRP(8-37), a CGRP antibody and an RNA-Spiegelmer on CGRP induced vasodilatation in the perfused and non-perfused rat middle cerebral artery. $\mathrm{Br} J$ Pharmacol 150:633-640. https://doi.org/10.1038/sj.bjp.0707134

35. Juhl L, Edvinsson L, Olesen J, Jansen-Olesen I (2007) Effect of two novel CGRP-binding compounds in a closed cranial window rat model. Eur J Pharmacol 567:117-124. https://doi.org/10.1016/j.ejphar.2007.04.004

36. Hoehlig K, Johnson KW, Pryazhnikov E et al (2015) A novel CGRP-neutralizing Spiegelmer attenuates neurogenic plasma protein extravasation. Br J Pharmacol 172:3086-3098. https://doi.org/10.1111/bph.13110

37. Zeller J, Poulsen KT, Sutton JE et al (2008) CGRP function-blocking antibodies inhibit neurogenic vasodilatation without affecting heart rate or arterial blood pressure in the rat. Br J Pharmacol 155:1093-1103. https://doi.org/10.1038/bjp. 2008.334

38. Schepelmann K, Ebersberger A, Pawlak M et al (1999) Response properties of trigeminal brain stem neurons with input from dura mater encephali in the rat. Neuroscience 90:543-554

39. Beise RD, Carstens E, Kohllöffel LU (1998) Psychophysical study of stinging pain evoked by brief freezing of superficial skin and ensuing short-lasting changes in sensations of cool and cold pain. Pain 74:275-286

40. Koulchitsky S, Fischer MJM, De Col R et al (2004) Biphasic response to nitric oxide of spinal trigeminal neurons with meningeal input in rat-possible implications for the pathophysiology of headaches. J Neurophysiol 92:1320-1328. https://doi.org/10.1152/jn.01210.2003

41. Fischer MJM (2010) Calcitonin gene-related peptide receptor antagonists for migraine. Expert Opin Investig Drugs 19:815-823. https://doi.org/10.1517/ 13543784.2010.490829

42. Will C, Messlinger K, Fischer MJM (2016) Vessel diameter measurements at the medullary brainstem in vivo as an index of trigeminal activity. Brain Res 1632:51-57. https://doi.org/10.1016/j.brainres.2015.12.013

43. Roch M, Messlinger K, Kulchitsky $V$ et al (2007) Ongoing activity in trigeminal wide-dynamic range neurons is driven from the periphery. Neuroscience 150:681-691. https://doi.org/10.1016/j.neuroscience.2007.09.032
44. Bennett AD, Chastain KM, Hulsebosch CE (2000) Alleviation of mechanical and thermal allodynia by CGRP(8-37) in a rodent model of chronic central pain. Pain 86:163-175

45. Sun R-Q, Lawand NB, Willis WD (2003) The role of calcitonin gene-related peptide (CGRP) in the generation and maintenance of mechanical allodynia and hyperalgesia in rats after intradermal injection of capsaicin. Pain 104:201-208

46. Kageneck C, Nixdorf-Bergweiler BE, Messlinger K, Fischer MJ (2014) Release of CGRP from mouse brainstem slices indicates central inhibitory effect of triptans and kynurenate. J Headache Pain 15:7. https://doi.org/10.1186/11292377-15-7

47. Wild V, Messlinger K, Fischer MJM (2015) Hydrogen sulfide determines HNOinduced stimulation of trigeminal afferents. Neurosci Lett 602:104-109. https://doi.org/10.1016/j.neulet.2015.06.056

48. Teepker M, Munk K, Mylius V et al (2009) Serum concentrations of s100b and NSE in migraine. Headache 49:245-252. https://doi.org/10.1111/j.15264610.2008.01228x

49. Holom VH, Messlinger K, Fischer MJM (2008) Temperature-dependent neuronal regulation of arterial blood flow in rat cranial dura mater. J Neurosci Res 86:158-164. https://doi.org/10.1002/jnr.21459

50. Strassman AM, Raymond SA, Burstein R (1996) Sensitization of meningeal sensory neurons and the origin of headaches. Nature 384:560-564. https://doi.org/10.1038/384560a0

51. Pethö G, Derow A, Reeh PW (2001) Bradykinin-induced nociceptor sensitization to heat is mediated by cyclooxygenase products in isolated rat skin. Eur J Neurosci 14:210-218

52. Mankarious S, Lee M, Fischer S et al (1988) The half-lives of IgG subclasses and specific antibodies in patients with primary immunodeficiency who are receiving intravenously administered immunoglobulin. J Lab Clin Med 112:634-640

\section{Submit your manuscript to a SpringerOpen ${ }^{\circ}$ journal and benefit from:}

- Convenient online submission

- Rigorous peer review

- Open access: articles freely available online

- High visibility within the field

- Retaining the copyright to your article

Submit your next manuscript at $>$ springeropen.com 